\title{
Integrative Estimation of Region Economic Stability as in the Case of the Russian Federation
}

\author{
Stanislava KONTSEVAYA ${ }^{*}$, Aleksander METLYAHIN ${ }^{2}$, Lyubov YARYGINA ${ }^{2}$, \\ Elvira ORLOVA ${ }^{2}$, Nadezhda NIKITINA ${ }^{2}$ and Lubos SMUTKA ${ }^{1}$ \\ 1 Czech University of Life Sciences, Prague, Czech Republic; s.konsevaya@mail.ru; smutka@pef.czu.cz \\ 2 Vologda State University, Vologda, Russia, a.metlyahin@mail.ru; iaryginalv@vogu35.ru; orlovaeo@mail.ru; \\ nikitina.vologda@list.ru \\ * Corresponding author: s.kontsevaya@mail.ru
}

\begin{abstract}
Economic stability of a region is an important object of control and analysis for the government. However, it is complex indicator and assessable complicatedly. The goal of the paper is a development of a methodology of region economic stability integrative estimation resistant to short dramatic fluctuations of definite years. The research is based on the data about 10 regions of the Russian Federation over the period of 2000-2018. Suggested methodology includes 12 components of economic stability based on 67 indicators. These indicators were chosen and subdivided into groups by three courses of threats i.e. social and demographical threat, production and economic threat, and infrastructural and supporting threat. Smoothing of coefficients is made by arithmetic progression with smoothing width equal to 5 years in order to obtain estimations resistant to short fluctuations. Integrative estimation helps compare indicators completely different by quality and quantity, to range regions and estimate influence extent of some actions or external shocks on economic stability dynamics, and to forecast further development of the scenario in the region. The integrative estimation was tested in the Vologda Region of the Russian Federation. The result of this test proves significant decrease of the economic stability over 18 years.
\end{abstract}

Keywords: regional analysis, agrifood, agriculture, methodology

\section{JELClassification: F52; Q18}

\section{Introduction}

The economic stability is a material basis of national safety. The objects of the economic stability comprise a government, regions, enterprises and a household sector. Economic stability estimation allows providing forthcoming support of regions being lower than a threshold level. This research deals with economic stability estimation at the regional level.

The economic stability can be described as a process when a human being or a society tends to reach tranquility and an ability to counteract threats within geographical or cultural space where they feel some kind of confidence that they have enough resources for satisfaction both present and future needs, and the threat potentially able to take up these resources never appears (Wiraszka \& Karpinska, 2020).

The key problem of economic stability estimation is multidimensional concept so it is complicated for measuring (Böhringer \& Jochem, 2007). The vast majority of scientists 
consider it as a combination of some aspects of physical and biotical environment, social and economic well-being (Efroymson et al., 2013). As an increasing of living standards is the main goal of region development, a safety matter is to be decided in this context too (Soltes, et al., 2020).

Modern approaches to economic stability estimation utilize environmental, social and economic conditions known as three key pillars of stability (Mori \& Christodoulou, 2012; Hacking \& Guthrie, 2008; Mayer, 2008). Some authors utilize more than 2600 indicators (Grooten et al., 2012). In order to increase complexity each input variable has often associated dataset comprising some observations. These huge amounts of data about different stability components are complicated in control, and their visualization is almost impossible without compression or reduction of the size.

Aggregative functions are one of methods to precise and simplify the data. Aggregating theory is a mathematical area which investigates shape and properties of an aggregative function. In environmental economics aggregating topic is presented in aggregating special relation (Su \& Ang, 2010,), and combination of information in separate sectors (Lenzen, 2007; Marinetal., 2012).

Indicators, composite indicators or aggregated indicators are used for simplification of multiple and complicated data sets and elaboration of estimation results. Though the choice of aggregative function is the key component of estimation development, in scientific works there are few patterns, which could work as examples of choosing appropriate aggregative function. The most explicit review of aggregative functions is presented in the research «Applications of aggregation theory to sustainability assessment» (Pollesch \& Dale, 2015).

Economic stability estimation differs from common social and economic development analysis by utilization of special methods of transformation of initial indicators and use of threshold values for qualitative analysis (Averina \& Buyanova, 2019).

Currently there are different approaches to estimation of economic stability level (Khasanov \& Korableva 2019; Mutchler et al., 2019; Dragojlovic et al., 2020; Akberdina \& Smirnova 2018, Korableva \& Karpov, 2017). As a rule, they are based upon indicative analysis that is quantitative and qualitative values identifying state and change of economic stability, and they are defined by combination of economic stability indicators.

Economic stability indicators have the following characteristic features:

- Identification of threats for economic stability in terms of quantity;

- Highly variable and sensitive, hence, they have high warning ability to warn of possible threats due to changed conditions of economic system functioning;

- they perform indicating functions only being altogether but not separated.

It should be noted that the most important characteristic of economic stability indicators is the specificity of their collaboration, which always exists but the only definite extent of threat reveals this collaboration and it starts alerting threat to the society (Senchagov, 2005).

Huge economic systems are stable and stagnant enough, so short time fluctuation should be neglected while making estimation, and only distorting properties of the economic system in the region should be taken into account. 
The goal of the paper is a development of a methodology of region economic stability integrative estimation resistant to short dramatic fluctuations of definite components.

The following tasks were set in order to reach the goal:

- Analysis of the key components of economic stability;

- Development of an algorithm for integrative estimation;

- Development of the method to obtain estimations resistant to short time fluctuations;

- Estimation economic stability dynamics as in the case of the Vologda Region of the Russian Federation.

The research is based on the information about 10 regions in the North-Western Federal District. Estimation was made by 12 components of economic stability based on 67 indicators. The data was taken over the period of 2000-2018. The source of the data is web-site Russian Federal State Statistic Service. Calculations were made in Microsoft Excel.

\section{Methodology}

\subsection{The Key Components of Economic Stability}

The methodology of estimation of economic stability level was built upon the classification of threats by areas combined into three main groups (Table 1).

Table 1. Subdivision of indicators into groups by economic stability courses

\begin{tabular}{|c|c|}
\hline Threat & Courses of stability \\
\hline Social and demographical & Demographical, migration, social, foodbased, environmental \\
\hline Production and economic & Production, investment, innovation, financial \\
\hline Infrastructural and supporting & Power-producing, infrastructural, foreign economic \\
\hline
\end{tabular}

Each of groups is characterized by the set of specific indicators and totally 67 indicators. The list of base indicators is presented in Appendix 1.

The following criteria, used as a base for choosing indicators, should be utilized for estimation of economic stability of the region:

- The ability of the population to expanded reproduction and to save its headcount;

- The ability of social and economic system of the region to hold out-migration of the regular population having high labor potential;

- The ability of social and economic system of the region to assimilate migrants;

- The conformity of the social standard of living to institutionally fixed standardized demands and improvement of this standard;

- The ability of nature resource potential of the terrain to withstand anthropogenic and industry-related stresses;

- Provision of the economy with strategic resources;

- Resource potential efficiency;

- The ability of the economy to function under expanded reproduction;

- Financial system stability; 
- Dependence of economy on import of the most important products, which can be manufactured in the region at the required level;

- Rationality of the foreign trade structure;

- Scientific potential support;

- Efficiency of the main schools of science in the region;

- Existence of the single economic area and inter-regional economic relations, respecting federal interests eliminating development of recessionist sentiments;

- Existence of economic and legal conditions eliminating criminal trends in the society;

- Efficiency of government regulation of economical processes.

Estimation of the level of economic stability of the region by specified criteria helps reveal threats in each of three abovementioned groups of economic stability. However, some of these criteria reveal status of stability courses belonging to different groups. For instance, provision of economy with strategic resources impacts production, investment, innovation and power-producing stability. Dependence of economy on import of the most important products, which can be manufactured in the region at the required level, proclaims challenges and threats of food and foreign economic security. It should be noted that in terms of the present research food security is the basis for economic stability analysis of the region. Keeping and increasing headcount of the stable population, improvement of living standards and provision with high quality food generate the basis for stable development of the region of the Russian Federation; hence, firstly these indicators provide security of regional economic system.

\subsection{Algorythm of Integrative Estimation}

Each course of economic stability has aggregated indicator which is calculated on the basis of some relative indicators by each specific course, and the total integrative indicator of the region is defined on the basis of aggregated indicators by each specific course.

Calculation of aggregated indicators supposes operating by relative specific indicator. In real case scenario the vast majority of specific indicators is calculated on different bases and can't be summed directly. Hence, all specific indicators by economic stability courses are rated in the following way.

Relative $\mathrm{j}$-indicator of $\mathrm{i}$-course of economic stability is calculated by the following equation:

$$
X_{i j}=1 \pm \frac{2}{\pi} \operatorname{atan}\left(\frac{x_{i j}-\bar{x}_{i j}}{\sigma_{i j}}\right)
$$

Where $x_{i j}$ - value of $\mathrm{j}$-indicator of $\mathrm{i}$-course of economic stability;

$\overline{\mathrm{x}}_{i j}$ - Average value of $\mathrm{j}$-indicator of $\mathrm{i}$-course of economic stability (threshold value);

$\sigma_{i j}$ - Standard deviation of the value $x_{i j}$ for comparable group of objects (neighboring regions).

The sign " + " is used when favorable value of the specific indicator exceeds the threshold value, otherwise the sign "-" should be put in the equation. 
If the calculation of aggregated indicators is made in terms of dynamic, appropriate values of relative indicators may be rated by average value of the current or the last year.

Such transformation helps guarantee satisfaction of the indicator $\mathrm{X}_{\mathrm{ij}}$ to the following conditions:

- $0<\mathrm{X}_{\mathrm{ij}}<2$ for any initial value of the specific value $x_{i j}$;

- $\mathrm{X}_{\mathrm{ij}}=1$ only in that case when the value of the specific indicator completely identical to the threshold value.

Both abovementioned conditions together with the way to obtain indicator proclaim existence of possible threats or challenges in decided course of economic stability if $\mathrm{X}_{\mathrm{ij}}<1$. Definite limits are to be defined a posteriori, and crossing of these limits by definite indicators signalizes threat with more or less extent of risk.

\subsection{The Method to Obtain Estimations Stable to Short Time Fluctuation}

Weighting coefficients in terms of time, presenting importance of the data of some year for effective indicator, should be assigned in order to calculate aggregated indicator with regard to dynamics. There are some methods of calculation weighting coefficients in terms of time $\delta_{t}$. Let us decide harmonic factor methods, modified exponential mean and arithmetic progression (Equation 2,3,4) with regard to calculate weighted mean for $T$ years.

Harmonic factor method.

According to this method the weights in terms of time are defined by the following equation:

$$
\delta_{t}=\frac{1}{T} \sum_{\tau=1}^{t} \frac{1}{T-\tau+1}
$$

Modified exponential mean.

Initially the parameter of smoothing $\lambda$ (initially it can be taken $\lambda=2 / \mathrm{T}$ ) is chosen. Then the weights of each year are calculated by the equation:

$$
\delta_{t}=\frac{\lambda(1-\lambda)^{T-t}}{1-(1-\lambda)^{T}}
$$

Arithmetic progression method.

This method is utilized in case of condition of constant difference between neighboring weighting coefficients. In this case coefficients in terms of time generate arithmetic progression. Assigning first term of the progression $\delta_{1}=a_{0}$, the progression difference $d$ is derived from the condition $\sum_{\tau=0}^{T-1} a_{\tau}=1$ :

$$
\frac{\left(2 a_{0}+d(T-1)\right)}{2} T=1, \text { then } \quad d=\frac{2}{T-1}\left(\frac{1}{T}-a_{0}\right) \text {, }
$$


To satisfy the condition $0<\delta_{t}<1$ it is necessary $0<a_{0}<\frac{1}{T}$.

Then the weighting coefficients in terms of time are calculated by the following equation:

$$
\delta_{t}=a_{0}+2 \frac{t-1}{T-1}\left(\frac{1}{T}-a_{0}\right)
$$

Choice of the method of calculation of weighting coefficients in terms of time $\delta_{t}$ depends of the goals of the research and variation of indicators afrom year to year.

Integrative indicator of economic stability of the region is defined on the basis of aggregated indicators calculated for course of economic stability by means of arithmetic or geometrical mean:

$$
X=\sum_{i=1}^{n} X_{i} \alpha_{i} ; X=\prod_{i=1}^{n} X_{i}^{\alpha_{i}} ; \quad \sum_{i=1}^{n} \alpha_{i}=1
$$

where $X_{i}$ - aggregated indicator of i-course of economic stability belonging to the interval $(0,2)$, relative units;

$i=1, \ldots, n$-number of courses representing economic stability of the region; $\alpha_{i}-$ the weighting coefficients of influence of indicators of i-course on the total level of economic stability in the region, relative units.

\section{Results}

Dynamics of economic stability level in the regions of the North-Western Federal District of the Russian Federation (including 10 regions i.e. the Karelia Republic, the Komi Republic, the Arkhangelsk Region, the Vologda Region, the Kaliningrad Region, the Leningrad Region, the Murmansk Region, the Novgorod Region, the Pskov Region, St. Petersburg) is estimated in order to test decided methodology. The estimation is made by 12 abovementioned components of economic stability based upon 67 indicators. The data belongs to the period of 19 years from 2000 till 2018. Smoothing period of 5 years was chosen in order to obtain more stable estimation. Consequent weighting coefficients calculated by different methods are presented in Table 2.

Table 2. Values of weighting coefficients for chronological mean of integrative indicators at $\mathrm{T}=5$

\begin{tabular}{|l|c|c|c|c|c|}
\hline \multicolumn{1}{|c|}{$\begin{array}{c}\text { Method of obtaining of the weighting } \\
\text { coefficients }\end{array}$} & $\mathbf{1}$ & $\mathbf{2}$ & $\mathbf{3}$ & $\mathbf{4}$ & $\mathbf{5}$ \\
\cline { 2 - 7 } & 0.040 & 0.090 & 0.157 & 0.257 & 0.457 \\
\hline Harmonic weights method & 0.056 & 0.094 & 0.156 & 0.260 & 0.434 \\
\hline Method of modified exponential mean & 0.150 & 0.175 & 0.200 & 0.225 & 0.250 \\
\hline Method of arithmetic progression &
\end{tabular}

Application of three decided methods of selecting weighting coefficients to the most economically developed region is presented in Figure 1. 


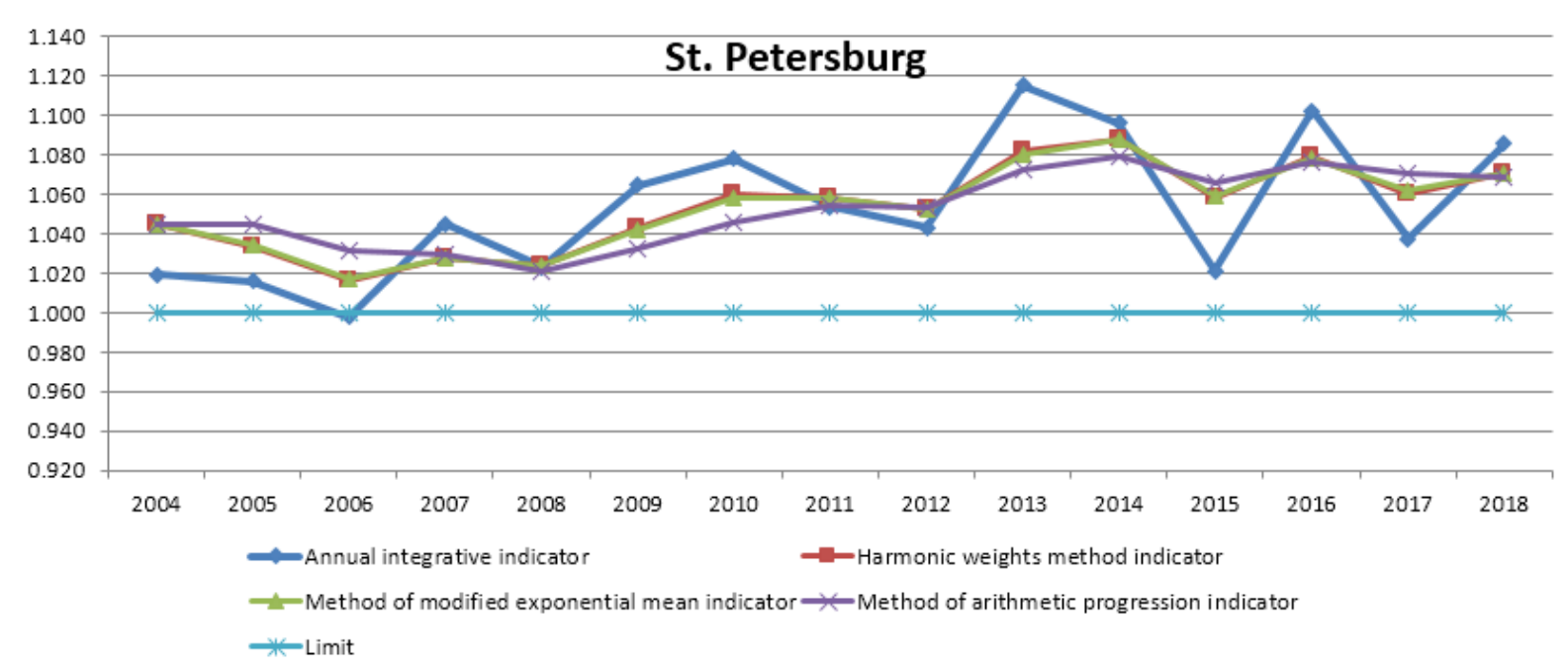

Figure 1. Integrative indicator of economic stability level, represented by different types of the weighting coefficients, in case of St. Petersburg

Obviously, the coefficients obtained by arithmetic progression provide the best smoothing. The same conclusion can be done by Figure 2 in case of the Vologda Region.

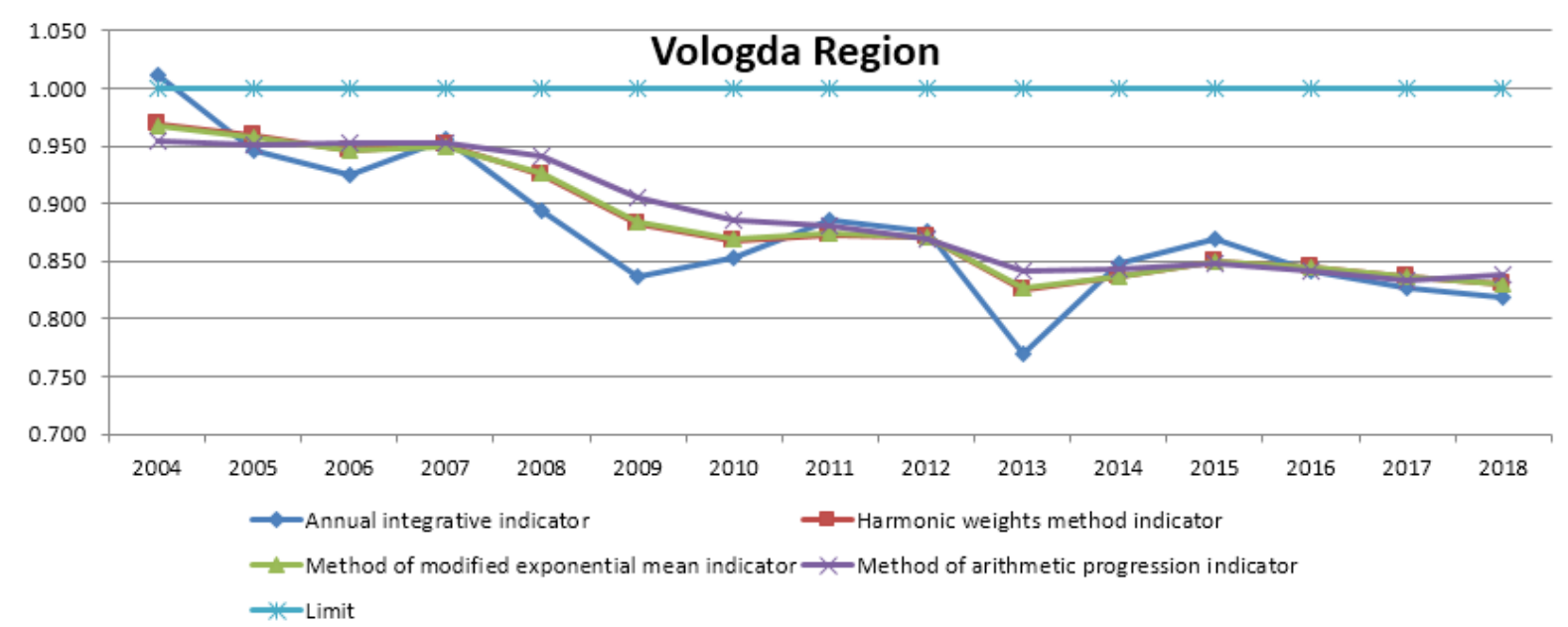

Figure 2. Integrative indicator of economic stability level, represented by different types of the weighting coefficients, in case of the Vologda Region

Annual consumption of food (meat, milk, sugar, vegetable oil, bread in $\mathrm{kg}$ and eggs in pcs.) per one person over 19 years represented by indicators for comparison is presented in Figure 3. Critical level of stability is 1 , less than 1 value means threat, and more than 1 value - consumption indicator is normal. 


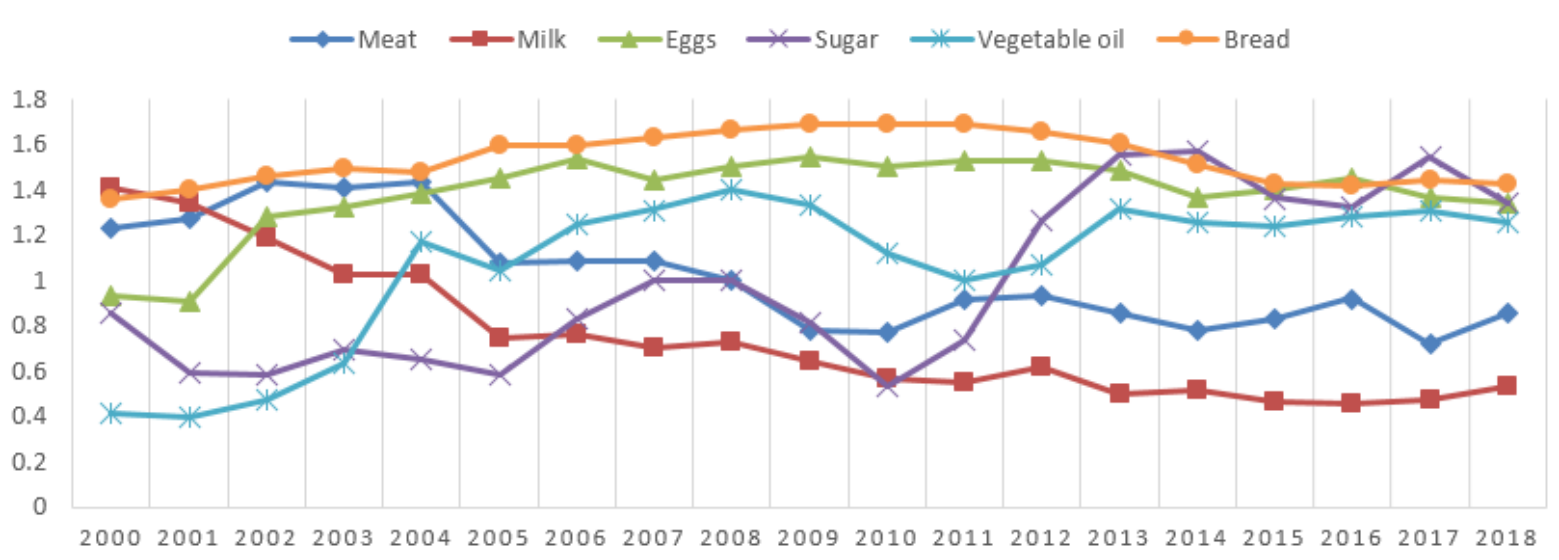

Figure 3. Annual consumption of main food products per 1 person in case of the Vologda Region integrative indicator

Obviously, provision with such main food products as meat and milk is steadily decreased.

Dynamics of integrative indicators represented by chronological means with weights obtained by arithmetic progression is presented on Figure 4 for 10 regions.

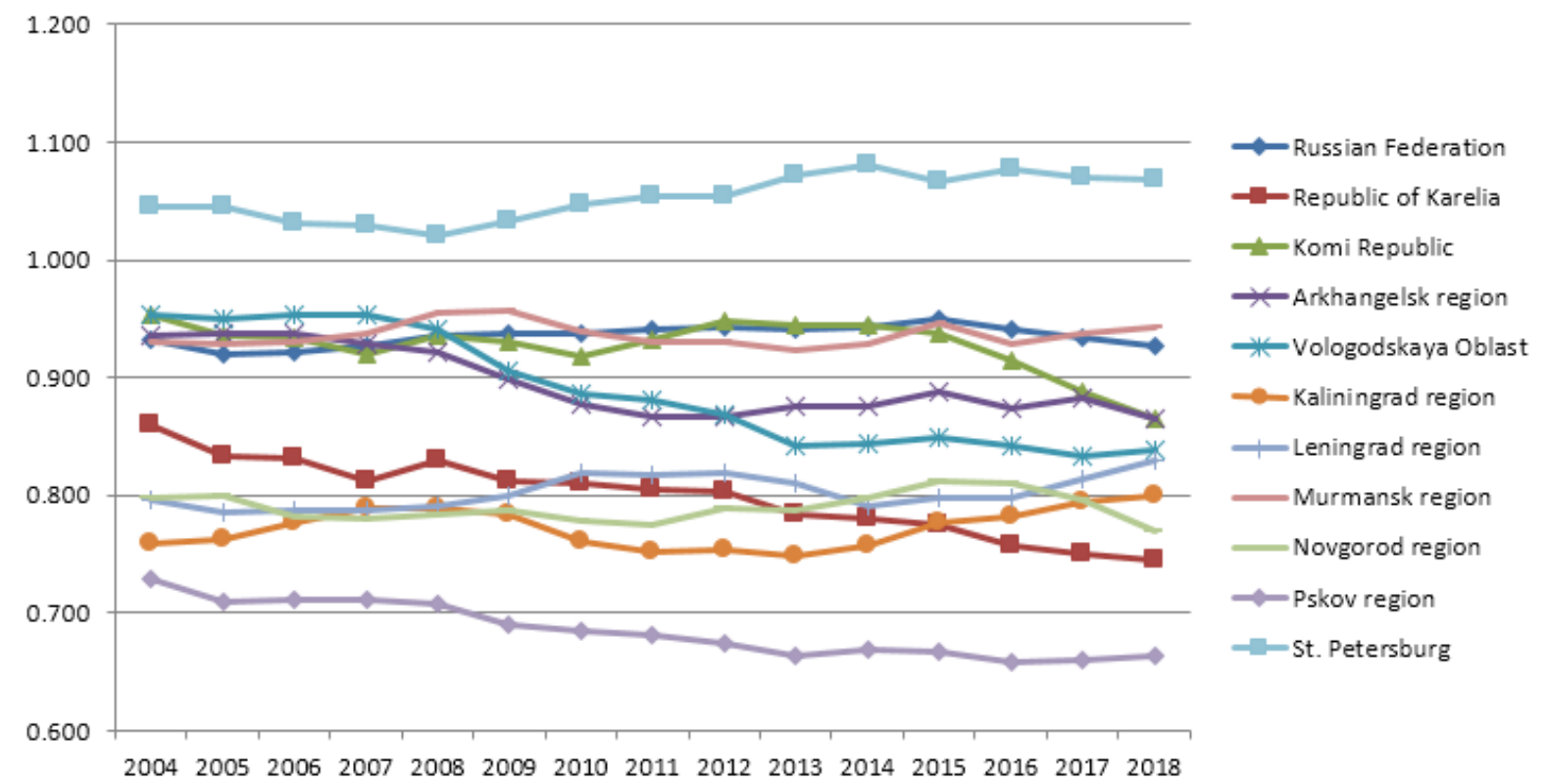

Figure4. Dynamics of integrative indicator of economic stability level over the period of 2000-2018

Value of integrative indicator for the decided regions proclaims steady economic stability in St. Peterburg only; at the same time other regions should determine actions to increase total economic stability and its courses that require some complex actions. 


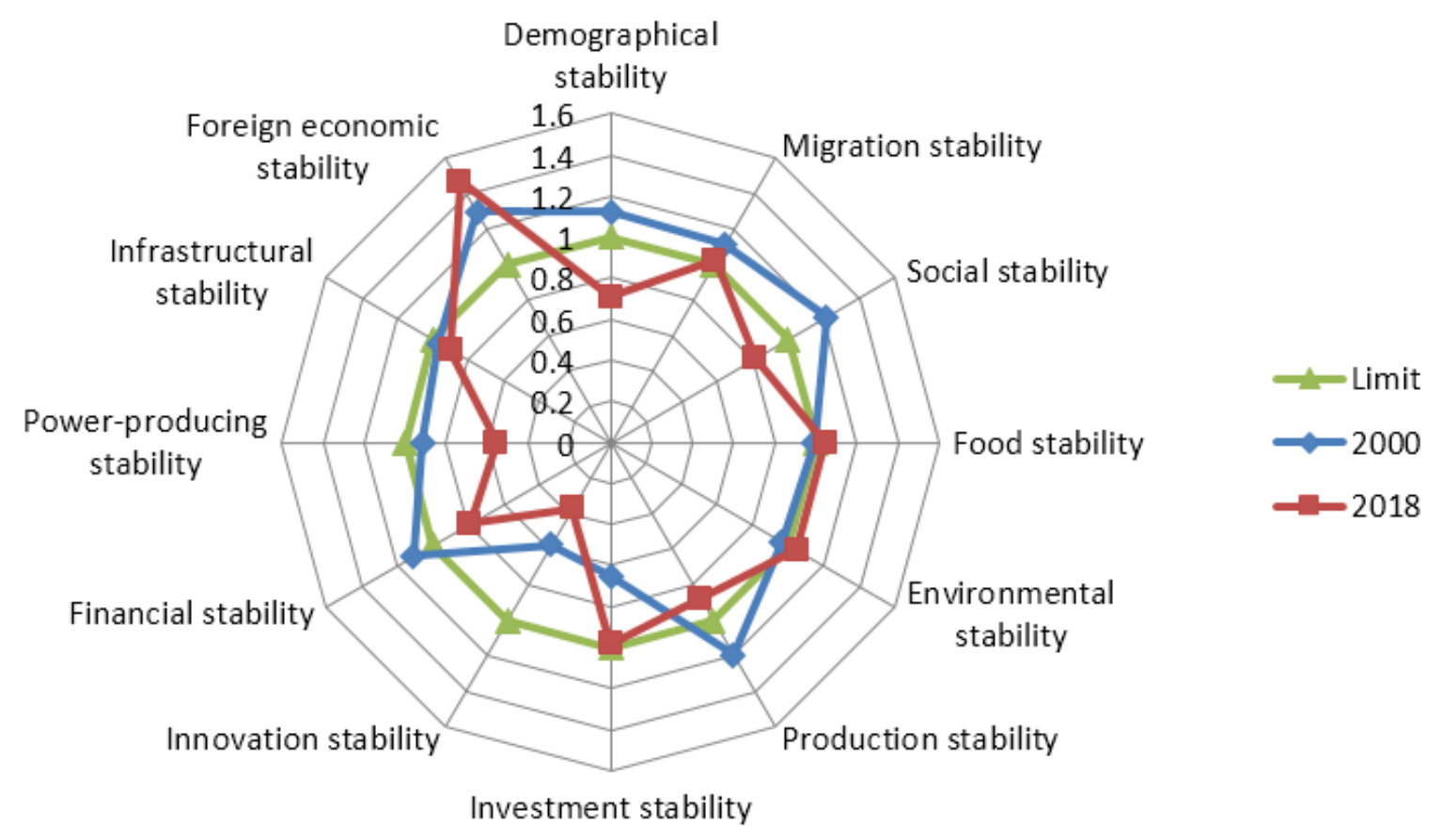

Figure 5. Aggregated indicators of economic stability represented by specific components for the Vologda Region

Analysis of phase-plane plot of the Vologda Region (Fig. 5) proclaims significant compression in almost each decided areas that obviously demonstrates threats in economic stability of the region.

Utilization of aggregated indicators helps reveal the most critical areas of economic stability and existence of challenges and threats for economic stability of the region. Level of economic stability was steadily decreasing within decided period in the Vologda Region.

Results obtained by this methodology coincide at a great extent with methodologies of other authors. Nevertheless, integrative estimation obtained by suggested methodology is less sensitive to short time and accidental fluctuations. This methodology clearly reveals critical components of economic stability which need careful attention of the government.

\section{Discussion}

Generation of a system of the indicators is the key objective for economic stability estimation of the region. Hence, there are some researches of Russian scientists on this topic. For instance, in 2014 specialists of Nizhny Novgorod State Technical University in the name of R. E. Alekseev together with Economics Institute of Russian Academy of Science suggested the system of indicators of economic stability of the region comprising 30 indicators (Senchagov, 2014). However, officially stated system of economic stability indicators on the regional level is still missing.

The basic level of economic stability is still a question for discussion too. In this research mean for 10 regions was taken as a minimum stability equal 1 . However, in opinion of (Korableva \& Karpov, 2017) utilization of official government data on minimum provision with each indicator is more correctly. For instance, according to the food security doctrine proper provision with milk and dairy products should be more than $90 \%$ of the total 
consumption value (Garant, 2020). Amount of the weighting coefficients by the courses of economic stability is also set on the basis of scientific experts' opinion when the most preferable aspects of economic stability are revealed. From one side, it brings definite extent of subjectivity, but, from another side, it takes into account experts' opinion for impartial assessment of economic stability.

Analysis of economic stability of the region with officially stated minimums and opinion of experts may be the topic of future researches.

\section{Conclusions}

Suggested integrative methodology, identifying economic stability, helps range regions by assigning definite range (number) in descending order of this indicator. Variation of the integrative indicator in dynamics provides estimation of the extent of influence of some actions or external shocking impacts on economic stability dynamics, and helps forecast further development of the situation in the region.

Acknowledgments: This research was supported by the grant of Internal Grant Agency (IGA) of Faculty of Economics and Management, Czech University of Life Sciences, project 2020A0015 entitled "Price changes on agrifood markets in post-Soviet countries under Russian import ban and sanctions".

\section{References}

Akberdina, V. V., \& Smirnova, O. P. (2018). Economic security of the region: assessment and prospects. Regional economy: theory and practice, 16(8), 1506-1517. https://doi.org/10.24891/re.16.8.1506

Averina, I. S., \& Buyanova, M. E. (2019). Problems and measures of innovative activity support in the system of economic security of the Volgograd region. In Proceedings of the Volgograd State University International Scientific Conference "Competitive, Sustainable and Safe Development of the Regional Economy". https://doi.org/10.2991/cssdre-19.2019.14

Böhringer, C., \& Jochem, P. E. (2007). Measuring the immeasurable - A survey of sustainability indices. Ecological Economics, 63(1), 1-8. https://doi.org/10.1016/j.ecolecon.2007.03.008

Dragojlovic, N., Michaux, K. D., Moumin, N. A., Li K. H., Talukder, Z., Hou, K., Mundy G., Stormer, A., Ngik, R., Green, T. J., \& Lynd, L. D. (2020). Economic Evaluation of an Enhanced Homestead Food Production Intervention for Undernutrition in Women and Children in Rural Cambodia. Global Food Security, 24. https://doi.org/10.1016/j.gfs.2019.100335

Efroymson, R. A., Dale, V. H., Kline, K. L., McBride, A. C., Bielicki, J. M., Smith, R. L., Parish, E. S., Schweizer, P. E., \& Shaw, D. M. (2013). Environmental Indicators of Biofuel Sustainability: What About Context? Environmental Management, 51(2), 291-306. https://doi.org/10.1007/s00267-012-9907-5

Garant (2020, January 21). Food security doctrine. Garant.ru. https://www.garant.ru/products/ipo/prime/doc/73338425/

Grooten, M., Almond, R., McLellan, R., \& World Wide Fund for Nature. (2012). Living planet report 2012: biodiversity, biocapacity and better choices. World Wide Fund for Nature. http://wwf.panda.org/about_our_earth/all_publications/living_planet_report/2012_lpr/

Hacking, T., \& Guthrie, P. (2008). A framework for clarifying the meaning of Triple Bottom-Line, Integrated, and Sustainability Assessment. Environmental Impact Assessment Review, 28(2), 73-89. https://doi.org/10.1016/j.eiar.2007.03.002

Khasanov, R. K., \& Korableva, A. A. (2019). Economic Security Index as a Tool to Assess the Development of Agroindustrial Regions. Ekonomicheskaya Politika, 14(6), 82-101. https://doi.org/10.18288/1994-5124-2019-6-82-101

Korableva, A. A., \& Karpov, V. V. (2017). Indicators of economic security of the region. Bulletin of the Siberian Institute of Business and Information Technologies, 3(23), 36-42.

Lenzen, M. (2007). Aggregation (in-)variance of shared responsibility: A case study of Australia. Ecological Economics, 64(1), 19-24. https://doi.org/10.1016/j.ecolecon.2007.06.025 
Marin, G., Mazzanti, M., \& Montini, A. (2012). Linking NAMEA and Input output for 'consumption vs. production perspective' analyses: Evidence on emission efficiency and aggregation biases using the Italian and Spanish environmental accounts. Ecological Economics, 74, 71-84.

https://doi.org/10.1016/j.ecolecon.2011.11.005

Mayer, A. L. (2008). Strengths and weaknesses of common sustainability indices for multidimensional systems. Environment International, 34(2), 277-291. https://doi.org/10.1016/j.envint.2007.09.004

Mori, K., \& Christodoulou, A. (2012). Review of sustainability indices and indicators: Towards a new City Sustainability Index (CSI). Environmental Impact Assessment Review, 32(1), 94-106. https://doi.org/10.1016/j.eiar.2011.06.001

Mutchler, J. E., Li, Y., \& Xu, P. (2019). How strong is the Social Security safety net? Using the Elder Index to assess gaps in economic security. Journal of Aging E Social Policy, 31(2), 123-137. https://doi.org/10.1080/08959420.2018.1465798

Pollesch, N., \& Dale, V. H. (2015). Applications of aggregation theory to sustainability assessment. Ecological Economics, 114, 117-127. https://doi.org/10.1016/j.ecolecon.2015.03.011

Russian Federal statistical website (2020) Russia in figures. Retrieved January 01, 2021, from https://rosstat.gov.ru/ Senchagova, V. K. (2005). Economic security of Russia: General course textbook (2nd ed.). Delo.

Senchagova, V. K. (2014). Economic security of Russian regions: monograph. Rastr-NN.

Soltes, V., Repkova Stofkova, K., \& Lenko, F. (2020). Socio-economic consequences of globalization on the economic development of regions in the context of security. SHS Web of Conferences, 74, 4-26. https://doi.org/10.1051/shsconf/20207404026

Su, B., \& Ang, B. W. (2010). Input-output analysis of CO2 emissions embodied in trade: The effects of spatial aggregation. Ecological Economics, 70(1), 10-18. https://doi.org/10.1016/j.ecolecon.2010.08.016

Wiraszka, P., \& Karpinska, U. (2020). Economicsecurity as an element of the region's development process on the example of communes of the Swietokrzyskie Voivodship. Baltic Journal of Economic Studies, 6(3) 67-75. https://doi.org/10.30525/2256-0742/2020-6-3-67-75

Appendix 1. Indicators divided by courses of economic stability (Part 1)

\begin{tabular}{|l|}
\hline I Social and demographical threats \\
\hline 1 Demographical: Crude birth rate (a number of newborns per 1,000 persons); Rate of natural increase per \\
1,000 persons; Dependency ratio (number of disabled persons per 1,000 persons of able-bodied persons); \\
Expectation of life at birth (years); Total fertility rate (number of children per 1 woman) \\
2 Migration: Net migration rate per 10,000 persons; Distribution of incomers by moving directions from \\
other regions (percent from total number of incomers); Distribution of incomers by moving directions from \\
abroad (percent from total number of incomers); Distribution of emigrants by moving directions from other \\
regions (percent from total number of emigrants); Migration ratio per 10,000 persons. \\
3 Social: Real earnings of the population (in percent from previous year); Ratio of per capita population \\
income to subsistence level, \%; Population with incomes less than subsistence level (in \% from total \\
population of the region); Average floor area per one person (m²); Number of persons died in traffic \\
accidents per 100,000 persons; Number of registered murders or assault to murder per 100,000 persons. \\
4 Food: Consumption of meat and meat products per 1 person in kg; Consumption of milk and dairy \\
products per 1 person in kg; Consumption of eggs per 1 person, pcs.; Consumption of sugar per 1 person, \\
kg; Consumption of vegetable oil per 1 person, kg; Consumption of bread per 1 person, kg; \\
$\mathbf{5}$ Environmental: Air pollution from stationary source, t/km²; Surface water pollution, $\mathrm{t} / \mathrm{km}^{2}$; Share of \\
recovered and incapacitated air pollutants in the total amount of air pollutants emitted by stationary \\
sources, \%
\end{tabular}


Appendix 1. Indicators divided by courses of economic stability (Part 2)

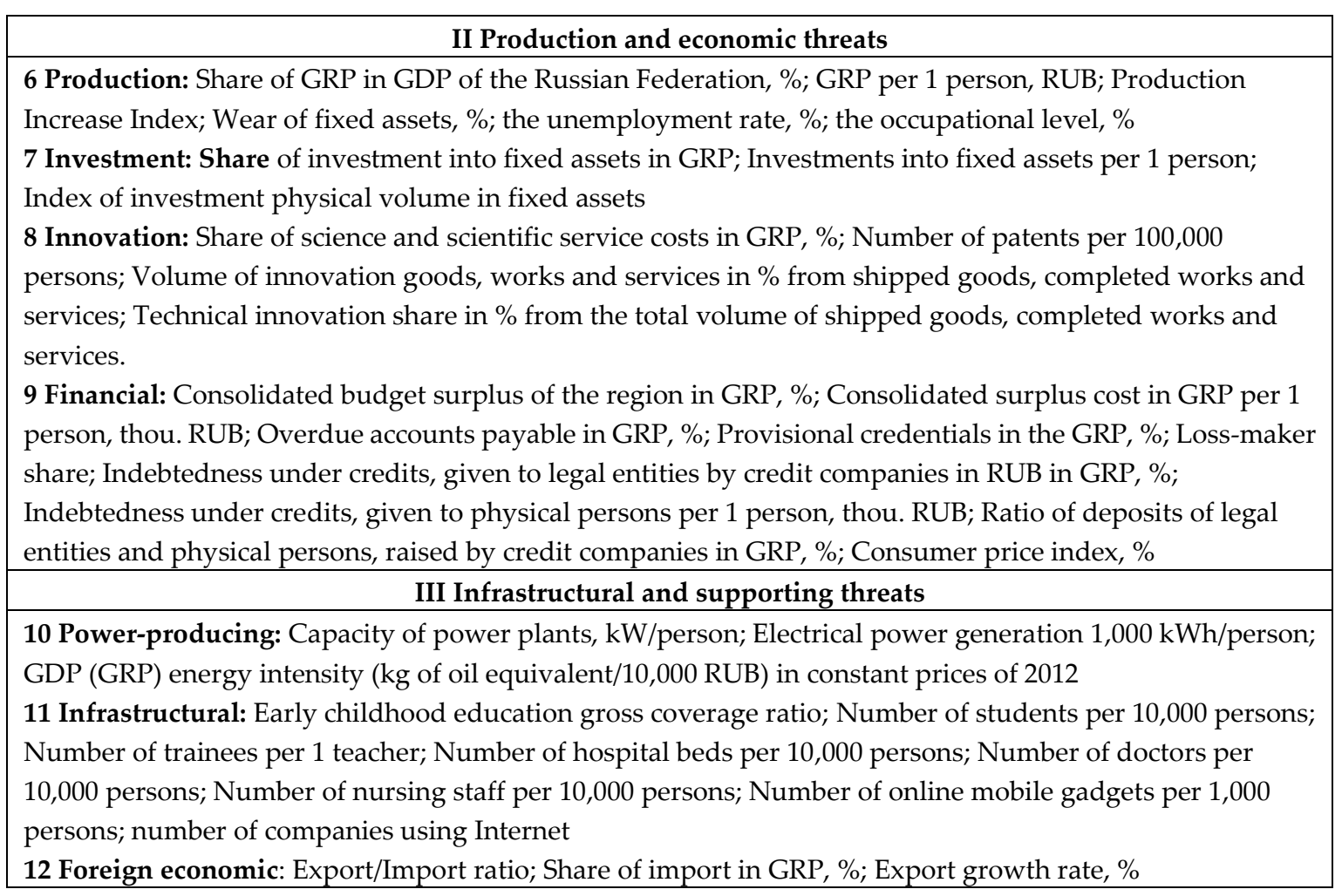

